\title{
Review
}

\section{Diaphragm: Pathophysiology and Ultrasound Imaging in Neuromuscular Disorders}

\author{
Abdallah Fayssoil ${ }^{\mathrm{a}, \mathrm{b}, *}$, Anthony Behin ${ }^{\mathrm{b}}$, Adam Ogna ${ }^{\mathrm{c}}$, Dominique Mompoint ${ }^{\mathrm{a}}$, Helge Amthor ${ }^{\mathrm{a}, \mathrm{d}}$, \\ Bernard Clair $^{\mathrm{a}}$, Pascal Laforet ${ }^{\mathrm{b}, \mathrm{d}}$, Arnaud Mansart ${ }^{\mathrm{a}}$, Helene Prigent ${ }^{\mathrm{a}, \mathrm{d}}$, David Orlikowski ${ }^{\mathrm{a}}$, \\ Tanya Stojkovic ${ }^{\mathrm{b}}$, Stéphane Vinit ${ }^{\mathrm{d}}$, Robert Carlier ${ }^{\mathrm{a}, \mathrm{d}}$, Bruno Eymard ${ }^{\mathrm{b}}$, Frederic Lofaso $^{\mathrm{a}, \mathrm{d}}$ \\ and Djillali Annane ${ }^{\mathrm{a}}$ \\ ${ }^{a}$ APHP, Raymond Poincare University Hospital, Garches, France \\ ${ }^{\mathrm{b}}$ Myology Institute, Pitié Salpetrière Hospital, Paris, France \\ ${ }^{\mathrm{c}}$ Lausanne University Hospital, Lausanne, Switzerland \\ ${ }^{\mathrm{d}}$ INSERM U1179, Versailles Saint-Quentin-en-Yvelines University, Montigny-le-Bretonneux, France
}

\begin{abstract}
Respiratory muscles are classically involved in neuromuscular disorders, leading to a restrictive respiratory pattern. The diaphragm is the main respiratory muscle involved during inspiration. Ultrasound imaging is a noninvasive, radiation-free, accurate and safe technique allowing assessment of diaphragm anatomy and function. The authors review the pathophysiology of diaphragm in neuromuscular disorders, the methodology and indications of diaphragm ultrasound imaging as well as possible pitfalls in the interpretation of results.
\end{abstract}

Keywords: Diaphragm, ultrasound, neuromuscular disorders

\section{INTRODUCTION}

Respiratory failure is one of the main causes of morbidity and mortality in patients with neuromuscular diseases (NMD). The diaphragm acts as the main respiratory muscle during inspiration and accounts for $70 \%$ of the inspired air volume during regular breathing [1]. Diaphragm muscle function is often impaired in NMD, leading to a restrictive respiratory pattern [2]. The diaphragm function can indirectly be analyzed by techniques such as fluoroscopy and chest radiography, which are non-specific and ionizing exams, and spirometric tests, which allow the

\footnotetext{
*Correspondence to: Abdallah Fayssoil, MD PhD, CHU Raymond Poincaré, APHP, Garches, France. Tel.: +33 0147107778; Fax: +33 01471077 83; E-mail: abdallah.fayssoil@aphp.fr.
}

assessment of global respiratory function [3]. Transdiaphragmatic pressure measurement remains the reference exam for determining diaphragm function; however, this method is invasive and technically challenging, and thus not routinely deployed [4]. Phrenic nerve conduction study provides assessment of phrenic nerve but requires some expertise. Ultrasound imaging (US) allows a non-invasive, radiation-free, accurate, reproducible and safe assessment of diaphragm anatomy and function [5-9].

In this manuscript, we review the pathophysiology of diaphragm and the principles of diaphragm sonography in patients suffering from NMD. We also considered the clinical indications of diaphragm sonography and discuss pitfalls in the interpretation of diaphragmatic US results. 


\section{DIAPHRAGM, ALVEOLAR HYPOVENTILATION AND NEUROMUSCULAR DISORDERS}

Diaphragm is a dome shaped fibro-muscular structure, composed of a central tendon surrounded by peripheral muscle fibers. Diaphragm is subdivided in two hemi diaphragms, each one innervated by the ipsilateral phrenic nerve (C3-C5 roots). Each hemi diaphragm consists in two parts, a costal part causing displacement of the anterior portion and a crural part that displaces the posterior portion [10], the latter presenting a greater respiratory excursion than the anterior portion. The diaphragm acts as the main respiratory muscle, in addition to scalene muscles and parasternal muscles that are the other principal respiratory muscles during quiet breathing [11]. The scalene muscles induce an upper thorax expansion, stabilizing the chest wall. During exercise, external intercostal muscles and sternocleidomastoid muscles, which constitute accessory respiratory muscles, are recruited.

During the inspiratory phase, diaphragm contraction creates a piston-like movement that decreases the pleural pressure. This induces a pressure gradient between atmosphere and alveoli, allowing inspiration of air and lung inflation. The diaphragmatic piston effect simultaneously increases the abdominal pressure and causes an outward movement of the abdominal wall. Diaphragm contraction increases not only the cranio-caudal lung size but also causes a cranial outward displacement of the lower ribs, associated with 2 forces [12]. The first force is applied by the diaphragm fibers (tangential orientation) at its insertion to the lower ribs. This action is particularly significant in patients with weak abdominal compliance. The second force is directly related to the transmission of abdominal pressure to the lower ribs in the zone of apposition [12]. The expiratory muscles include internal intercostal muscles and abdominal muscles. Expiration is a passive movement during quiet breathing. The underlying force of this passive movement is generated by the elastic recoil of the respiratory system [13]. However, during exercise or forced expiration and during cough, the expiratory muscles are requested and participate in driving the end expiratory volume below the functional residual capacity (FRC).

In NMD, the progressive decrease in respiratorysystem compliance may result from limited movement during spontaneous yawns and sighs, which normally prevent stiffening of the chest wall [14] while also spreading surfactant over the air-fluid interface and re-inflating areas of atelectasis [15]. In addition, the upper airway musculature may be affected by swallowing disorders and airway obstruction during the inspiratory phase [16]. The imbalance between the load imposed on the inspiratory muscles and their strength leads to alveolar hypoventilation and hypercapnia [17]. Respiratory function has also a central regulatory drive that may be affected in NMD, with a reduction in chemo-sensibility that results from chronic hypercapnia [18-20]. The failure of the expiratory muscles in NMD causes insufficient cough and thereby reduces clearance of airway secretions. As a consequence, the risk for acute respiratory failure increases in NMD patients [17].

In summary, motion and contractile force of the diaphragm may be affected by pathological alterations of the following anatomical structures:

- Central nervous system

- Phrenic nerve

- Neuromuscular junction

- Diaphragm muscle

- Thoracic cage

- Upper abdomen

In patients on mechanical ventilation, the positive end expiratory pressure (PEEP) level also decrease diaphragmatic motion by increasing the end expiratory lung volume and thereby lowering the diaphragmatic dome at the end of expiration [21].

\section{EXPLORATIONS OF THE DIAPHRAGM}

In parallel with the functional respiratory tests, techniques have been developed in order to explore the diaphragm. They can be separated into:

- Volitional and non-volitional tests

- Invasive and non-invasive methods

- Specific and non-specific investigations.

Each test has advantages and disadvantages in clinical practice. The non-invasive simple tests include the measurement of vital capacity (VC), of maximal inspiratory pressure (MIP), of Sniff nasal inspiratory pressure (SNIP). These tests are volitional and nonspecific. Spirometry is used as the first line to assess global respiratory function in patients with NMD by the analysis of the vital capacity (VC), that reflects the inspiratory and expiratory muscle function. However, spirometry is not sensitive to detect early involvement of respiratory muscles in NMD since $\mathrm{VC}$ is 
in the normal range until a significant decline of respiratory muscle strength occurs [22]. Spirometry may give indirect information about diaphragmatic function. A drop of $\mathrm{VC}>20 \%$ from sitting to supine position is frequent in cases of diaphragmatic weakness, reaching a 30\% drop in patients with a paralyzed hemi-diaphragm, and can be used as an indirect assessment of diaphragmatic function [23]. The other respiratory muscle functional tests rely on the measurement of maximal inspiratory pressure (MIP) and sniff nasal inspiratory pressure [24]. MIP reflects inspiratory muscle strength and depends on the lung volume at which the test is performed; MIP is classically measured from residual volume [25]. Sniff nasal inspiratory pressure (SNIP) measurement is performed using a natural maneuver and reflects the strength of the diaphragm [26]. Twitch mouth pressure during magnetic phrenic nerve stimulation is a non-volitional test that can be used for detection of diaphragm muscle weakness [27]. However, this method requires dedicated equipment that limits routine utilization, and some expertise is required, for example to identify the optimal timing for stimulation to avoid airway collapse [28].

The specific invasive test for diaphragmatic function analysis relies on the trans-diaphragmatic pressure swing ( $p d i)$ measurement. This latter can be achieved under three conditions:

- Quiet spontaneous breathing (QSB),

- Sniff maneuver

- Bilateral magnetic phrenic nerve stimulation [29].

Trans-diaphragmatic pressure measurement during QSB and magnetic phrenic nerve stimulations are non-volitional invasive tests, whereas Sniff maneuver $p d i$ is a volitional invasive test $[3,30]$. However, pdi measurement is limited in clinical practice requiring intra-gastric and intra-esophageal probe insertion [31]. An indirect noninvasive and non-volitional test for the diaphragmatic function assessment is the optoelectronic plethysmography (OEP). This technique evaluates the abdominal displacement during QSB [32]. However, this method requires dedicated equipment, which is not routinely available, can only be performed in the supine position and does not allow determination of the underlying cause of diaphragmatic dysfunction [32].

In radiology, techniques for diaphragm exploration include fluoroscopy, ultrasound, computed tomography (CT) and magnetic resonance imaging (MRI) $[33,34]$. Fluoroscopy used to be the traditional exam used for analyzing diaphragm function. However, this method needs the patient to be in a vertical position that limits its use in neuromuscular disorders and also exposes patients to irradiation [35]. Diaphragmatic $\mathrm{CT}$ and MRI are reference imaging tests for exploring diaphragm in radiology. For instance, in late onset Pompe disease (LOPD), diaphragm atrophy and diaphragm elevation have already been reported [33]. An additional value of CT results from the fact that lung abnormalities like atelectasis can be diagnosed during the same exam. However, the thin muscle layer of the diaphragm limits the use of MRI as a diagnostic tool, notably in the presence of diaphragm atrophy [34]. Moreover, this method fails if patients require permanent mechanical ventilation in the supine position. Ultrasound imaging is a non-volitional and volitional imaging test that can be performed at the bedside. It provides information regarding diaphragm function and can be repeatedly performed without causing discomfort or adverse effects.

Phrenic neurophysiological study can be performed in patients with neuropathy or phrenic injury. This technique may be invasive (needle recording diaphragm motor units) or non-invasive (phrenic nerve conduction) [36]. However, this method requires some expertise that limits routine utilization.

\section{PRINCIPLES OF DIAPHRAGM ULTRASOUND IMAGING}

Haber first described diaphragm sonography in 1975 [37]. Since then, many reports have been published on this method, particularly for its use in the intensive care unit (ICU). Two ultrasound methods are classically used to assess diaphragmatic function: the analysis of the dome excursion with $\mathrm{M}$ mode approach, and/or the evaluation of diaphragmatic thickness and thickening during inspiration by analyzing the apposition zone.

\section{Diaphragm excursion from $M$ mode and correlation with spirometry}

From the anterior subcostal view, diaphragm sonography is performed during quiet respiration and during deep breathing. For this, a cardiac probe with lower frequency transducer or an abdominal convex probe is usually used. The right diaphragm is analyzed through the liver window and the left diaphragm through the spleen window. It is easier to assess 


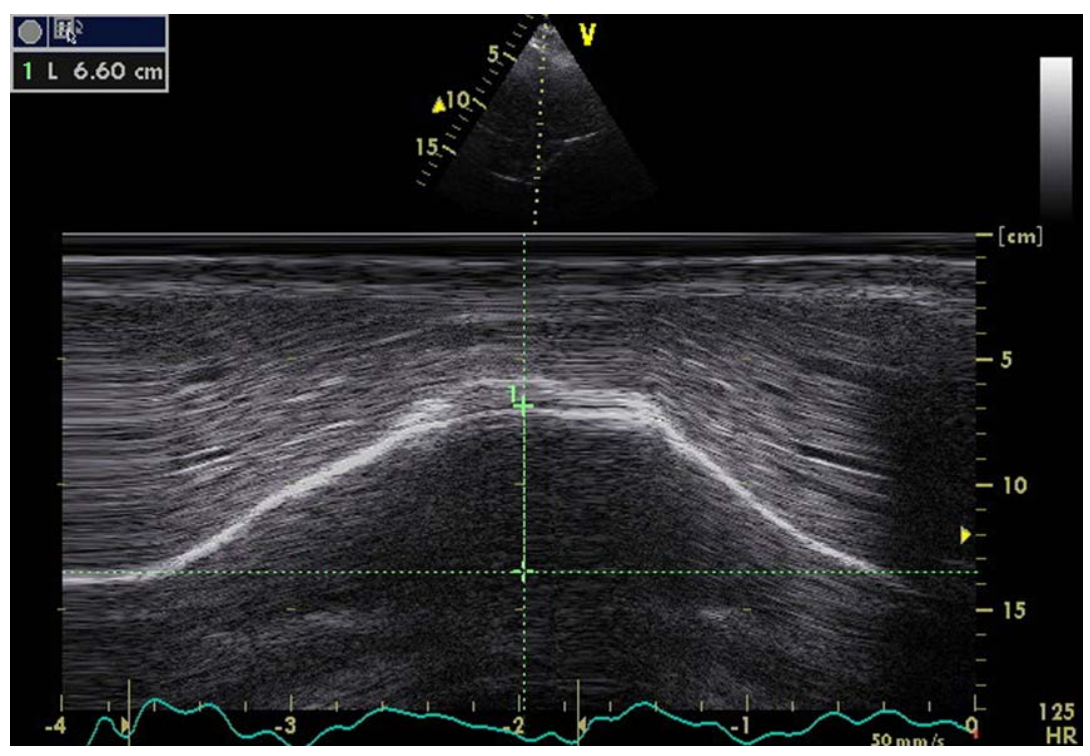

Fig. 1. Diaphragm M mode ultrasound imaging from an anterior subcostal view for the measurement of the hemi diaphragm motion during inspiration. Note the normal right hemi-diaphragmatic excursion reaching $66 \mathrm{~mm}$ during deep inspiration.

the right hemi-diaphragm rather than the left hemidiaphragm because of limited left spleen window and interference from stomach [38]. The transducer is placed in the anterior subcostal region between the mid clavicular and anterior axillary lines. The ultrasound beam should reach the posterior part of the diaphragm. In the B mode view, the diaphragm is identified as an echogenic line between the interface of the lung and liver or spleen [6]. Then, $\mathrm{M}$ mode is performed to record diaphragmatic excursion during respiration (Fig. 1) [39, 40].

Diaphragm sonography can be performed during quiet breathing or deep inspiration or sniff maneuver. In pediatric population, the two hemi-diaphragms can be assessed at the same time from a sub-xiphoid view with a curvilinear transducer [39]. Diaphragmatic motion analysis with sonography has already been reported in pediatric [41] and adult populations [37, 41, 42], leading to the publication of normal values [42-46]. In normal subjects, correlation between diaphragmatic inspiratory course and inspiratory volume is reported to reach 0.9 in some studies $[38,42]$. Table 1 summarizes the main studies reporting normal values in diaphragm ultrasound.

\section{Apposition zone analysis with echography and correlation with spirometry}

Diaphragm thickness and thickening can be assessed at the zone of apposition (ZA) during inspiration and expiration, using a linear higher frequency transducer $[3,5]$. The zone of apposition is the chest wall area where the lower rib cage reaches the abdominal contents. The probe is positioned between the antero-axillary and mid-axillary lines, perpendicular to the chest wall. With B mode, the hemi-diaphragm is identified beneath the intercostal muscles as a hypo-echogenic layer of muscle tissue located between two hyper-echogenic lines (the pleural line and the peritoneal line) (Fig. 2). Diaphragm muscle thickness depends on lung volumes and normally increases during inspiration $[4,47]$. Diaphragmatic thickening is assessed by the thickening fraction (TF), defined as (thickness at end inspiration - thickness at end expiration)/thickness at end expiration. The relation between TF and lung volume has been reported to be linear [4].

Normal values have been reported in healthy subjects. Diaphragmatic thickness in the zone of apposition increases during a maximal inspiratory maneuver with good correlation between diaphragm thickening ratio and maximal inspiratory pressure $(r=-0.82, p<0.01)$ [5]. Wait et al. [4] reported a mean diaphragmatic thickness value of $2.2+-0.4 \mathrm{~mm}$ in a study that included 10 healthy men, placing the transducer between the ribs in the ninth lateral interspace. They also described an increase in diaphragm thickness in the zone of apposition with lung volume increase. Ueki et al. [5] reported a mean thickness of $1.7+-0.2 \mathrm{~mm}$ at functional 
Table 1

Normal values of diaphragm motion, thickness and thickening ratio with ultrasound imaging

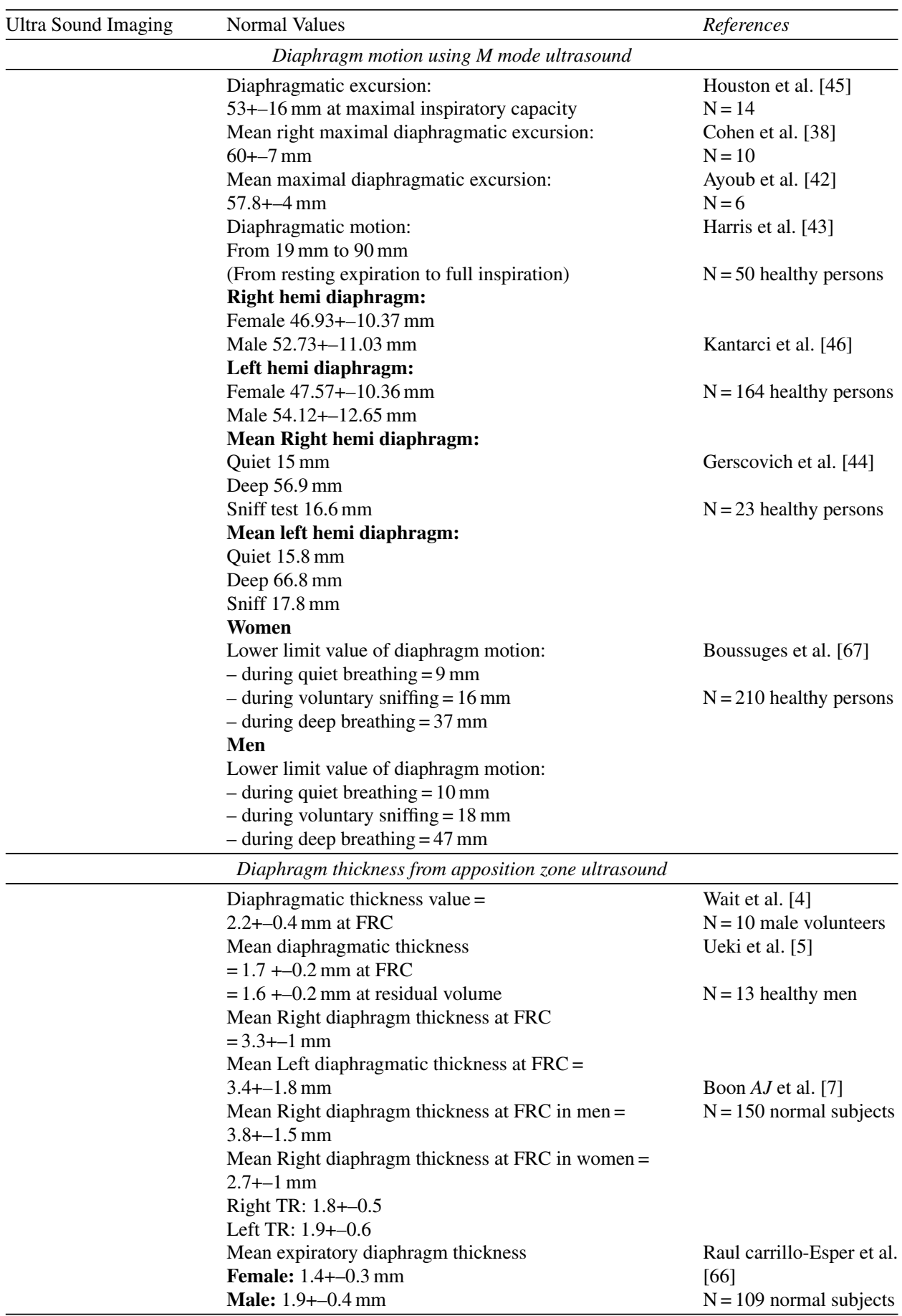

FRC: functional residual capacity. N: number of patients. TR: thickening ratio = diaphragm thickness at maximum inspiration/diaphragm thickness at end expiration.

residual capacity (FRC). In a study which included 150 normal subjects, Boon et al. [7] reported a lower limit of normal diaphragm thickness (at end expiratory or FRC) of $1.5 \mathrm{~mm}$ with an increase of at least $20 \%$ of diaphragm thickness from FRC to total lung capacity. Mean right diaphragm thickness 


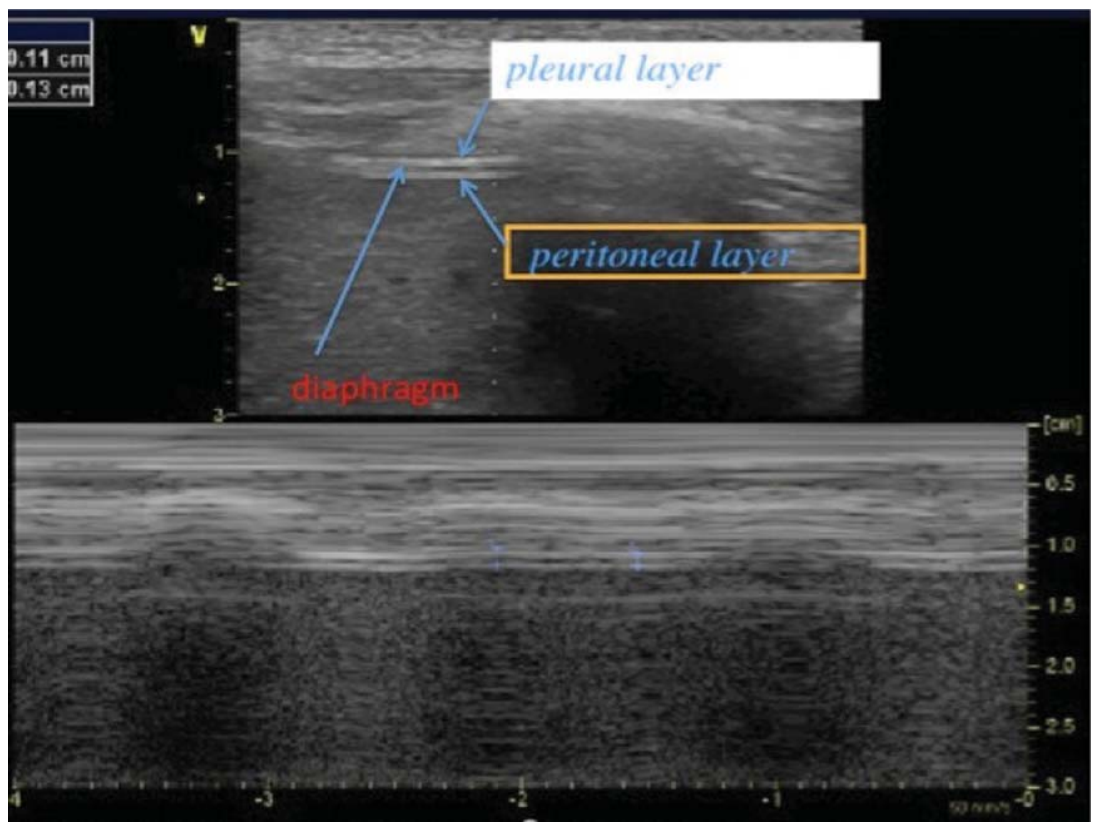

Fig. 2. 2D mode ultrasound imaging from the zone of apposition for the measurement of diaphragm thickness. The diaphragm is located beneath the intercostal muscles and we can distinguish three layers: a hypo-echogenic thick layer (diaphragm muscle) surrounded by two hyper-echogenic lines (pleural layer and peritoneal layer). Here is a reduced diaphragm thickness $(1.3 \mathrm{~mm})$ in a patient with Duchenne muscular dystrophy.

at FRC was $3.3+-1 \mathrm{~mm}$ and mean left diaphragm thickness at FRC was $3.4+-1.8 \mathrm{~mm}$ in the same study [7]. In normal subjects, a side to side hemi diaphragmatic thickness difference $<0.33 \mathrm{~cm}$ at rest has been reported [7]. Table 1 summarizes principal studies reporting normal values in diaphragm ultrasound.

\section{CLINICAL APPLICATIONS OF DIAPHRAGM ULTRASOUND IMAGING}

The assessment of respiratory muscle function is of paramount interest in patients with neuromuscular disorders. In patients with NMD, respiratory symptoms are subtle and usually appear late in the clinical course of the disease, partly because of the limited mobility of patients due to peripheral muscle weakness, except in the case of acute respiratory failure due to infection. Clinical presentation is quite variable in cases of diaphragmatic failure. Orthopnea may be present and paradoxical abdominal motion may be observed during inspiration, with the abdomen moving inward while the rib cage expands.

Chest $X$ ray classically shows asymmetric diaphragm elevation in the case of unilateral diaphragm paralysis, but it is less useful in NMD patients presenting with bilateral diaphragmatic dysfunction. Spirometry usually reveals a moderately restrictive respiratory pattern or significant VC decrease in the case of bilateral diaphragmatic paralysis [48]. The decrease in VC correlates with weakness of both inspiratory and expiratory muscles. Residual volume may increase with increasing failure of expiratory muscles.

Diaphragm sonography is already routinely used in ICU patients and may be useful in patients with myopathy for diagnosis and monitoring of diaphragm function [49]. In the ICU, mechanical ventilation can rapidly lead to diaphragmatic impairment and thinning [50]. Diaphragm ultrasound has been used to help predict extubation failure in weaning from mechanical ventilation [51]. A diaphragmatic excursion $>25 \mathrm{~mm}$ increased the likelihood of success of SBT (spontaneous breathing trial) in mechanically ventilated patients [52]. Also, a diaphragm thickening fraction $>30-36 \%$ during SBT increased the likelihood of success of SBT [52]. In cardiac surgery, the phrenic nerve may be injured, causing diaphragm paralysis that can be assessed by diaphragm ultrasound [53], in addition with neurophysiological study.

Also, after cervical surgery, diaphragm ultrasound associated with phrenic nerve conduction study and 
diaphragm electromyogram can help the clinician diagnose phrenic nerve injury.

In the neuromuscular field, recent data confirm the potential applications of diaphragm ultrasound in clinical practice. In a recent study including 37 patients with amyotrophic lateral sclerosis (ALS), myopathies and neuropathies, an excellent correlation was found between VC and diaphragm thickness $(r=0.74)$ [54]. However, specific studies need to be performed since pathophysiologic processes are different in ALS and myopathies.

Diaphragmatic ultrasound can be performed at the bedside and in patients sitting in a wheelchair. It may help clinicians to diagnose diaphragm weakness, paralysis [55] or phrenic neuropathy [56]. Diaphragm paralysis may be confirmed by the calculation of diaphragm thickening (TF). A diaphragm TF $<20 \%$ is consistent with diaphragmatic paralysis, according to $\mathrm{McCool}$ [55]. Clinical applications of this method are extensive, ranging from diseases affecting the central nervous system to disorders affecting the phrenic nerve. Diaphragm ultrasound may be used to assess diaphragm muscle weakness in myopathies such as Duchenne muscular dystrophy (DMD), Pompe disease, facio-scapulo-humeral dystrophy (FSHD), Ullrich myopathy, myotonic dystrophy type I, nemaline myopathy and steroid induced myopathy. De Bruin et al. [57] reported increased diaphragmatic thickness at end expiration using sonography in pediatric DMD patients, presumably due to pseudohypertrophy. Respiratory impairment is classical in patients with FSHD [58] and abdominal muscles are involved, often leading to a lordotic posture. Spirometric and maximal respiratory pressures measurement may be difficult in FSHD because peri-oral leaks occur due to facial muscle weakness. Diaphragmatic sonography may thus be of major usefulness in many cases of FSHD. Respiratory failure is also frequent in patients with collagen VI-related myopathies with a $2.6 \%$ annual decline of forced vital capacity in patients with Ullrich congenital muscular dystrophy [59]. Late-onset Pompe disease is a metabolic myopathy with frequent diaphragm involvement [60]. Diaphragmatic monitoring is essential in this disease and may be achieved using sonography. In patients with diseases that affect the central nervous system (ALS, poliomyelitis, spinal muscular atrophy, transverse myelitis, cervical spine disease), or the peripheral nervous system (ALS, Guillain Barré syndrome, neuropathy, Lyme disease, Parsonage Turner syndrome) or the neuromuscular junction (myasthenia gravis, Lambert-Eaton syndrome), diaphragm ultrasound may be useful in evaluating diaphragm weakness or paralysis [61, 62].

Diaphragm thickness measured with sonography correlates with the size of the diaphragm compound muscle action potential in response to phrenic nerve stimulation in ALS [63]. In myasthenia gravis, diaphragm sonography combined with electromyogram (EMG) and phrenic nerve conduction study is helpful in identifying phrenic nerve injury, particularly after thymectomy [64].

The diaphragm assessment by needle EMG is sometimes difficult and carries the potential risk of pneumothorax [65]. The use of ultrasound guidance for needle placement may enhance the accuracy and safety of EMG. In the pediatric population, diaphragm ultrasound adds significant value for diagnosing diaphragmatic hernia, post-traumatic hernia and diaphragm paralysis.

\section{Limits of diaphragm ultrasound imaging}

Some concerns about the results of diaphragm sonography have to be pointed out in clinical practice. It is sometimes difficult to visualize the left hemi-diaphragm, particularly in patients with elevated BMI [39]. Moreover, diaphragmatic excursion depends on the maximal voluntary inspiratory effort of patients and is influenced by the position of the subject, being greater in the supine position than in the sitting position for the same inspiratory volume [5]. Diaphragm motion is affected by the abdominal contents and pressure that limit diaphragm displacement [45]. Finally, current reference values have been established from studies that included small or moderate number of volunteers that limit global generalization.

For the interpretation of results, it is essential to take into account some limitations:

- Diaphragm thickness is different at different intercostal spaces

- Diaphragm thickness varies from FRC to TLC

- History of abdominal or thoracic surgery may influence diaphragm motion

- Permanent mechanical ventilation affects diaphragm thickness and motion

- Hemi-diaphragm motion may be different from one side to the other; to avoid this limitation, it is essential to perform the ultrasound exam using identical ultrasound beam position and direction. 


\section{CONCLUSION}

Diaphragm analysis with ultrasound has advantages including its nonionizing radiation, noninvasive technique, ease of use, reproducibility, speed of testing, and low cost in comparison with other diaphragmatic tests. There are many indications, including the assessment of patients with reduced inspiratory capacity, paradoxical respiration, asymmetric chest radiography appearance, unexplained dyspnea particularly when supine. In patients with suspicion of diaphragm paralysis or phrenic nerve injury after surgery, diaphragm sonography may be indicated in association with diaphragm EMG and phrenic NCS.

In neurological practice, diaphragm ultrasound may be indicated in a variety of clinical scenarios, ranging from peripheral neuromuscular disease to central disorders. This technique may also be used for monitoring the diaphragm in clinical trials of medications or treatments directed at improving muscle function.

\section{CONFLICTS OF INTEREST}

The authors have no conflict to report.

\section{REFERENCES}

[1] Mead J, Loring SH. Analysis of volume displacement and length changes of the diaphragm during breathing. J Appl Physiol Respir Environ Exerc Physiol. 1982;53(3):750-5.

[2] Bushby K, Finkel R, Birnkrant DJ, Case LE, Clemens PR, Cripe L, Kaul A, Kinnett K, McDonald C, Pandya S, Poysky J, Shapiro F, Tomezsko J, Constantin C, DMD Care Considerations Working Group. Diagnosis and management of Duchenne muscular dystrophy, part 2: Implementation of multidisciplinary care. Lancet Neurol. 2010;9(2):177-89.

[3] Chavhan GB, Babyn PS, Cohen RA, Langer JC. Multimodality imaging of the pediatric diaphragm: Anatomy and pathologic conditions. Radiographics. 2010;30(7):1797817.

[4] McCool FD, Tzelepis GE. Dysfunction of the diaphragm. N Engl J Med. 2012;366(10):932-42.

[5] Wait JL, Nahormek PA, Yost WT, Rochester DP. Diaphragmatic thickness-lung volume relationship in vivo. J Appl Physiol (1985). 1989;67(4):1560-8.

[6] Ueki J, De Bruin PF, Pride NB. In vivo assessment of diaphragm contraction by ultrasound in normal subjects. Thorax. 1995;50(11):1157-61.

[7] Kantarci F, Mihmanli I, Demirel MK, Harmanci K, Akman C, Aydogan F, Mihmanli A, Uysal O. Normal diaphragmatic motion and the effects of body composition: Determination with M-mode sonography. J Ultrasound Med. 2004;23(2):255-60.

[8] Boon AJ, Harper CJ, Ghahfarokhi LS, Strommen JA, Watson JC, Sorenson EJ. Two-dimensional ultrasound imaging of the diaphragm: Quantitative values in normal subjects. Muscle Nerve. 2013;47(6):884-9.

[9] Cohn D, Benditt JO, Eveloff S, McCool FD. Diaphragm thickening during inspiration. J Appl Physiol (1985). 1997;83(1):291-6.

[10] De Troyer A, Sampson M, Sigrist S, Macklem PT. The diaphragm: Two muscles. Science. 1981;213(4504):237-8.

[11] Lo Mauro A, Aliverti A. Physiology of respiratory disturbances in muscular dystrophies. Breathe (Sheff). 2016; 12(4):318-327.

[12] Troyer AD1, Wilson TA2. Action of the diaphragm on the rib cage. J Appl Physiol (1985). 2016;121(2):391-400.

[13] De Troyer A, Kelly S, Macklem PT, Zin WA. Mechanics of intercostal space and actions of external and internal intercostal muscles. J Clin Invest. 1985;75(3):850-7.

[14] Estenne M, Heilporn A, Delhez L, Yernault JC, De Troyer A. Chest wall stiffness in patients with chronic respiratory muscle weakness. The American Review of Respiratory Disease. 1983;128:1002-7.

[15] Gibson GJ, Pride NB, Davis JN, Loh LC. Pulmonary mechanics in patients with respiratory muscle weakness. The American Review of Respiratory Disease. 1977;115: 389-95.

[16] Eikermann M, Vogt FM, Herbstreit F, Vahid-Dastgerdi M, Zenge MO, Ochterbeck C, de Greiff A, Peters J. The predisposition to inspiratory upper airway collapse during partial neuromuscular blockade. Am J Respir Crit Care Med. 2007;175(1):9-15.

[17] Ambrosino N, Carpenè N, Gherardi M. Chronic respiratory care for neuromuscular diseases in adults. Eur Respir J. 2009;34(2):444-51.

[18] Baydur A. Respiratory muscle strength and control of ventilation in patients with neuromuscular disease. Chest. 1991;99(2):330-8.

[19] Johnson DC, Kazemi H. Central control of ventilation in neuromuscular disease. Clin Chest Med. 1994;15(4): 607-17.

[20] Caruana-Montaldo B, Gleeson K, Zwillich CW. The control of breathing in clinical practice. Chest. 2000;117(1):205-25.

[21] Beaumont M, Lejeune D, Marotte H, Harf A, Lofaso F Effects of chest wall counterpressures on lung mechanics under high levels of CPAP in humans. J Appl Physiol (1985). 1997;83(2):591-8.

[22] Vincken W, Elleker MG, Cosio MG. Determinants of respiratory muscle weakness in stable chronic neuromuscular disorders. Am J Med. 1987;82(1):53-8

[23] Fromageot C, Lofaso F, Annane D, Falaize L, Lejaille M, Clair B, Gajdos P, Raphaël JC. Supine fall in lung volumes in the assessment of diaphragmatic weakness in neuromuscular disorders. Arch Phys Med Rehabil. 2001;82(1):123-8.

[24] Syabbalo N. Assessment of respiratory muscle function and strength. Postgrad Med J. 1998;74(870):208-15.

[25] Evans JA, Whitelaw WA. The assessment of maximal respiratory mouth pressures in adults. Respir Care. 2009;54(10): 1348-59.

[26] Fauroux B, Aubertin G, Cohen E, Clément A, Lofaso F Sniff nasal inspiratory pressure in children with muscular, chest wall or lung disease. Eur Respir J. 2009;33(1):113-7.

[27] Laghi F, Tobin MJ. Relationship between transdiaphragmatic and mouth twitch pressures at functional residual capacity. Eur Respir J. 1997;10(3):530-6.

[28] Santos DB, Desmarais G, Falaize L, Ogna A, Cognet S, Louis B, Orlikowski D, Prigent H, Lofaso F. Twitch mouth pressure for detecting respiratory muscle weakness in suspicion of neuromuscular disorder. Neuromuscul Disord. 2017. 
[29] Man WD, Moxham J, Polkey MI. Magnetic stimulation for the measurement of respiratory and skeletal muscle function. Eur Respir J. 2004;24(5):846-60.

[30] Miller JM, Moxham J, Green M. The maximal sniff in the assessment of diaphragm function in man. Clin Sci (Lond). 1985;69(1):91-6.

[31] Pellegrini N, Laforet P, Orlikowski D, Pellegrini M, Caillaud C, Eymard B, Raphael JC, Lofaso F. Respiratory insufficiency and limb muscle weakness in adults with Pompe's disease. Eur Respir J. 2005;26(6):1024-31.

[32] Meric H, Falaize L, Pradon D, Orlikowski D, Prigent H, Lofaso F. 3D analysis of the chest wall motion for monitoring late-onset Pompe disease patients. Neuromuscul Disord. 2016;26(2):146-52.

[33] Gaeta M, Barca E, Ruggeri P, Minutoli F, Rodolico C, Mazziotti S, Milardi D, Musumeci O, Toscano A. Late-onset Pompe disease (LOPD): Correlations between respiratory muscles CT and MRI features and pulmonary function. Mol Genet Metab. 2013;110(3):290-6.

[34] Gaeta M, Mileto A, Mazzeo A, Minutoli F, Di Leo R, Settineri N, Donato R, Ascenti G. Blandino MRI findings, patterns of disease distribution, and muscle fat fraction calculation in five patients with Charcot-Marie-Tooth type $2 \mathrm{~F}$ disease. A Skeletal Radiol 2012;41(5):515-24.

[35] Young DA, Simon G. Certain movements measured on inspiration-expiration chest radiographs correlated with pulmonary function studies. Clin Radiol. 1972;23(1):37-41.

[36] Resman-Gaspersc A, Podnar S. Phrenic nerve conduction studies: Technical aspects and normative data. Muscle Nerve. 2008;37(1):36-41.

[37] Haber K, Asher M, Freimanis AK. Echographic evaluation of diaphragmatic motion in intra-abdominal diseases. Radiology. 1975;114(1):141-4.

[38] Cohen E, Mier A, Heywood P, Murphy K, Boultbee J, Guz A. Excursion-volume relation of the right hemidiaphragm measured by ultrasonography and respiratory airflow measurements. Thorax. 1994;49(9):885-9.

[39] Sarwal A, Walker FO, Cartwright MS. Neuromuscular ultrasound for evaluation of the diaphragm. Muscle Nerve. 2013;47(3):319-29.

[40] Urvoas E, Pariente D, Fausser C, Lipsich J, Taleb R, Devictor D. Diaphragmatic paralysis in children: Diagnosis by TM-mode ultrasound. Pediatr Radiol. 1994;24(8):564-8.

[41] Trinavarat P, Riccabona M. Potential of ultrasound in the pediatric chest. Eur J Radiol. 2014;83(9):1507-18.

[42] Ayoub J, Metge L, Dauzat M, Lemerre C, Pourcelot L, Préfaut C, Lopez FM. Diaphragm kinetics coupled with spirometry. M-mode ultrasonographic and fluoroscopic study; preliminary results. J Radiol. 1997;78(8):563-8.

[43] Harris RS, Giovannetti M, Kim BK. Normal ventilatory movement of the right hemidiaphragm studied by ultrasonography and pneumotachography. Radiology. 1983; 146(1):141-4.

[44] Gerscovich EO, Cronan M, McGahan JP, Jain K, Jones CD, McDonald C. Ultrasonographic evaluation of diaphragmatic motion. J Ultrasound Med. 2001;20(6):597-604.

[45] Houston JG, Angus RM, Cowan MD, McMillan NC, Thomson NC. Ultrasound assessment of normal hemidiaphragmatic movement: Relation to inspiratory volume. Thorax. 1994;49(5):500-3.

[46] Kantarci F, Mihmanli I, Demirel MK, Harmanci K, Akman C, Aydogan F, Mihmanli A, Uysal O. Normal diaphragmatic motion and the effects of body composition: Determination with M-mode sonography. J Ultrasound Med. 2004;23(2): 255-60.
[47] McCool FD, Conomos P, Benditt JO, Cohn D, Sherman CB, Hoppin Jr FG. Maximal inspiratory pressures and dimensions of the diaphragm. Am J Respir Crit Care Med. 1997;155(4):1329-34.

[48] Mier-Jedrzejowicz A, Brophy C, Moxham J, Green M. Assessment of diaphragm weakness. Am Rev Respir Dis. 1988;137(4):877-83.

[49] O'Gorman CM, O'brien TG, Boon AJ. Utility Of diaphragm ultrasound in myopathy. Muscle Nerve. 2017;55(3): 427-9.

[50] Grosu HB, Lee YI, Lee J, Eden E, Eikermann M, Rose KM. Diaphragm muscle thinning in patients who are mechanically ventilated. Chest. 2012;142(6):1455-60.

[51] Matamis D, Soilemezi E, Tsagourias M, Akoumianaki E, Dimassi S, Boroli F, Richard JC. Brochard L Sonographic evaluation of the diaphragm in critically ill patients. Technique and clinical applications. Intensive Care Med. 2013;39(5):801-10.

[52] Mayo P, Volpicelli G, Lerolle N, Schreiber A, Doelken P, Vieillard-Baron A. Ultrasonography evaluation during the weaning process: The heart, the diaphragm, the pleura and the lung. Intensive Care Med. 2016;42(7):1107-17.

[53] Lerolle N, Guérot E, Dimassi S, Zegdi R, Faisy C, Fagon JY, Diehl JL. Ultrasonographic diagnostic criterion for severe diaphragmatic dysfunction after cardiac surgery. Chest. 2009;135(2):401-7.

[54] Noda Y, Sekiguchi K, Kohara N, Kanda F, Toda T. Ultrasonographic diaphragm thickness correlates with compound muscle action potential amplitude and forced vital capacity. Muscle Nerve. 2016;53(4):522-7.

[55] Gottesman E, McCool FD. Ultrasound evaluation of the paralyzed diaphragm. Am J Respir Crit Care Med. 1997; 155(5):1570-4.

[56] Summerhill EM, El-Sameed YA, Glidden TJ, McCool FD. Monitoring recovery from diaphragm paralysis with ultrasound. Chest. 2008;133(3):737-43.

[57] De Bruin PF, Ueki J, Bush A, Khan Y, Watson A, Pride NB. Diaphragm thickness and inspiratory strength in patients with Duchenne muscular dystrophy. Thorax. 1997;52(5):472-5.

[58] Santos DB, Boussaid G, Stojkovic T, Orlikowski D, Letilly N, Behin A, Butel S, Lofaso F, Prigent H. Respiratory muscle dysfunction in facioscapulohumeral muscular dystrophy. Neuromuscul Disord. 2015;25(8):632-9.

[59] Foley AR, Quijano-Roy S, Collins J, Straub V, McCallum M, Deconinck N, Mercuri E, Pane M, D’Amico A, Bertini E, North K, Ryan MM, Richard P, Allamand V, Hicks D, Lamandé S, Hu Y, Gualandi F, Auh S, Muntoni F, Bönnemann CG. Natural history of pulmonary function in collagen VI-related myopathies. Brain. 2013;136(Pt 12): 3625-33.

[60] Meric H, Falaize L, Pradon D, Orlikowski D, Prigent H, Lofaso F. 3D analysis of the chest wall motion for monitoring late-onset Pompe disease patients. Neuromuscul Disord. 2016;26(2):146-52.

[61] Boon AJ, Sekiguchi H, Harper CJ, Strommen JA, Ghahfarokhi LS, Watson JC, Sorenson EJ. Sensitivity and specificity of diagnostic ultrasound in the diagnosis of phrenic neuropathy. Neurology. 2014;83(14):1264-70.

[62] Pinto S, Pinto A, de Carvalho M. Phrenic nerve studies predict survival in amyotrophic lateral sclerosis. Clin Neurophysiol. 2012;123(12):2454-9.

[63] Pinto S, Alves P, Pimentel B, Swash M, de Carvalho M. Ultrasound for assessment of diaphragm in ALS. Clin Neurophysiol. 2016;127(1):892-7. 
[64] Salati M, Cardillo G, Carbone L, Rea F, Marulli G, Brunelli A, Voltolini L, Gotti G, Rocco G. Iatrogenic phrenic nerve injury during thymectomy: The extent of the problem. J Thorac Cardiovasc Surg. 2010;139(4):e77-8.

[65] Chen R, Collins S, Remtulla H, Parkes A, Bolton CF. Phrenic nerve conduction study in normal subjects. Muscle Nerve. 1995;18(3):330-5.

[66] Carrillo-Esper R, Pérez-Calatayud ÁA, Arch-Tirado E, Díaz-Carrillo MA, Garrido-Aguirre E, Tapia-Velazco R,
Peña-Pérez CA, Espinoza-de Los Monteros I, MezaMárquez JM, Flores-Rivera OI, Zepeda-Mendoza AD, de la Torre-León T. Standardization of sonographic diaphragm thickness evaluations in healthy volunteers. Respir Care. 2016;61(7):920-4.

[67] Boussuges A, Gole Y, Blanc P. Diaphragmatic motion studied by m-mode ultrasonography: Methods, reproducibility, and normal values. Chest. 2009;135(2):391-400. 